\title{
Correction to: Sex and Selling: Agent Gender and Bargaining Power in the Resale Housing Market
}

\section{Duong T. Pham ${ }^{1}$ - Geoffrey K. Turnbull ${ }^{2}$ B Bennie D. Waller ${ }^{3}$ []}

Published online: 24 March 2021

(c) Springer Science+Business Media, LLC, part of Springer Nature 2021

\section{Correction to: J Real Estate Finan Econ https://doi.org/10.1007/s11146-020-09811-3}

The original version of this article unfortunately contained a mistake. The word "Bargaining" was missing from the article title. The accurate title should be "Sex and Selling: Agent Gender and Bargaining Power in the Resale Housing Market."

The original article has been corrected.

Publisher's Note Springer Nature remains neutral with regard to jurisdictional claims in published maps and institutional affiliations.

The online version of the original article can be found at https://doi.org/10.1007/s11146-020-09811-3

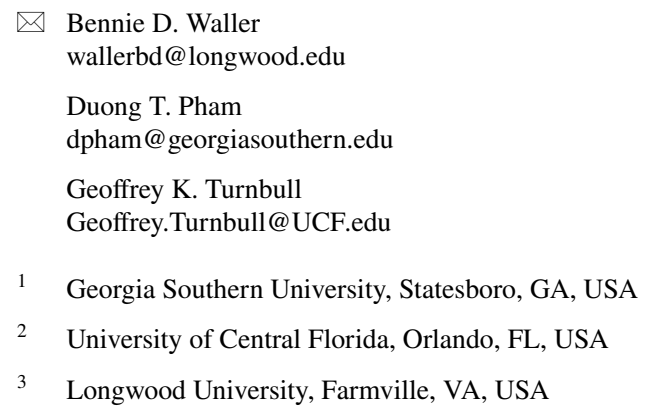

